\title{
Matrix Metalloproteinase-9 Is Required for Hippocampal Late-Phase Long-Term Potentiation and Memory
}

\author{
Vanja Nagy, ${ }^{1 \star}$ Ozlem Bozdagi, ${ }^{1 *}$ Anna Matynia, ${ }^{2}$ Marcin Balcerzyk, ${ }^{3}$ Pawel Okulski, ${ }^{3}$ Joanna Dzwonek, ${ }^{3}$ Rui M. Costa, ${ }^{2}$ \\ Alcino J. Silva, ${ }^{2}$ Leszek Kaczmarek, ${ }^{3}$ and George W. Huntley ${ }^{1}$ \\ ${ }^{1}$ Fishberg Department of Neuroscience, The Mount Sinai School of Medicine, New York, New York 10029-6574, 2Departments of Neurobiology, Psychiatry, \\ and Psychology, and Brain Research Institute, University of California, Los Angeles, Los Angeles, California 90095, and ${ }^{3}$ Laboratory of Molecular \\ Neurobiology, Nencki Institute, 02-093 Warsaw, Poland
}

\begin{abstract}
Matrix metalloproteinases (MMPs) are extracellular proteases that have well recognized roles in cell signaling and remodeling in many tissues. In the brain, their activation and function are customarily associated with injury or pathology. Here, we demonstrate a novel role for MMP-9 in hippocampal synaptic physiology, plasticity, and memory. MMP-9 protein levels and proteolytic activity are rapidly increased by stimuli that induce late-phase long-term potentiation (L-LTP) in area CA1. Such regulation requires NMDA receptors and protein synthesis. Blockade of MMP-9 pharmacologically prevents induction of L-LTP selectively; MMP-9 plays no role in, nor is regulated during, other forms of short-term synaptic potentiation or long-lasting synaptic depression. Similarly, in slices from MMP-9 null-mutant mice, hippocampal LTP, but not long-term depression, is impaired in magnitude and duration; adding recombinant active MMP-9 to null-mutant slices restores the magnitude and duration of LTP to wild-type levels. Activated MMP-9 localizes in part to synapses and modulates hippocampal synaptic physiology through integrin receptors, because integrin function-blocking reagents prevent an MMP-9-mediated potentiation of synaptic signal strength. The fundamental importance of MMP-9 function in modulating hippocampal synaptic physiology and plasticity is underscored by behavioral impairments in hippocampal-dependent memory displayed by MMP-9 null-mutant mice. Together, these data reveal new functions for MMPs in synaptic and behavioral plasticity.
\end{abstract}

Key words: proteolysis; extracellular matrix; integrins; synaptic plasticity; fear conditioning; LTD

\section{Introduction}

Matrix metalloproteinases (MMPs) are a large family of mostly secreted, extracellularly acting endopeptidases, the canonical substrates of which are proteins of the extracellular matrix as well as some non-matrix proteins such as adhesion proteins (Sternlicht and Werb, 2001). In many tissues, including the brain, MMPs and their natural inhibitors, the tissue inhibitors of metalloproteinases (TIMPs), act critically in regulating functional and structural remodeling of cellular architecture in the context of pathophysiology (Yong et al., 2001). The consequences of proteolytic cleavage of target molecules by MMPs are varied and complex and are thought broadly to include both changes in physical constraints of the pericellular environment as well as signaling through liberation of normally sequestered molecules

Received 0ct. 12, 2005; revised Dec. 10, 2005; accepted Jan. 1, 2006.

This work was supported by National Institutes of Health (NIH) Grant NS34659, the United States Public Health Service (G.W.H.), and Polish Ministry of Science Grant PBZ-MIN-005/P04/2002 (L.K.). Confocal laser scanning microscopy was performed at the MSSM-Microscopy Shared Resource Facility, supported by NIH-National Cancer Institute Grant R24-CA095823 and National Science Foundation Major Research Instrumentation Grant DBI9724504. We are grateful for helpful discussions with Drs. Liliana Ossowski, Deanna Benson, Susana R. Neves, Panayiotis Tsokas, and Bob Blitzer. We also thank Kari Rimell for excellent technical assistance.

*V.N. and O.B. contributed equally to this work.

Correspondence should be addressed to Dr. George W. Huntley, Fishberg Department of Neuroscience, Box 1065 The Mount Sinai School of Medicine, 1425 Madison Avenue, New York, NY 10029-6574. E-mail: george.huntley@mssm.edu.

DOI:10.1523/JNEUROSCI.4359-05.2006

Copyright $\odot 2006$ Society for Neuroscience $\quad$ 0270-6474/06/261923-12\$15.00/0 such as growth factors, or exposure of latent bioactive peptide fragments (Nagase and Woessner, 1999).

In the brain, functional and structural synaptic remodeling is not limited to injury but is also a component of normal neuronal physiology. In the hippocampus, a structure critical for certain types of learning and memory (Eichenbaum et al., 1992), highly organized synaptic circuits link neurons into functional networks that are dynamically maintained, allowing for new associations appropriate for learning and memory (Shapiro and Eichenbaum, 1999). It is tacitly recognized that such flexibility in functional circuitry reflects activity-dependent changes in the strength of the synaptic signal (synaptic plasticity), which can be increased [long-term potentiation (LTP)] or decreased [long-term depression (LTD)] from minutes to days or longer (Bliss and Lømo, 1973; Bliss and Collingridge, 1993). Mechanistically, rapid changes in synaptic efficacy arise through posttranslational modifications of presynaptic and postsynaptic proteins that regulate neurotransmitter release or receptor function (Liao et al., 1992; Silva et al., 1992; Shi et al., 1999; Castillo et al., 2002). Synaptic plasticity that lasts more than a few hours requires, in addition, transcription and translation (Frey et al., 1988; Nguyen et al., 1994; Impey et al., 1996) and has been associated with structural remodeling of synaptic contacts (Engert and Bonhoeffer, 1999; Toni et al., 1999; Bozdagi et al., 2000; Nägerl et al., 2004; Zhou et al., 2004).

There is now compelling evidence that signals that orchestrate 
synaptic structural and functional changes associated with synaptic plasticity derive, in part, from cell-surface adhesion proteins as well as proteins of the extracellular matrix with which they interact (Benson et al., 2000; Dityatev and Schachner, 2003). For example, integrin receptors, which transduce cell-cell or cell-matrix interactions (Hynes, 1992), are required for longterm maintenance of hippocampal LTP (Staubli et al., 1990; Bahr et al., 1997; Chun et al., 2001) and are essential for certain kinds of hippocampal-dependent memory (Chan et al., 2003). Although the precise upstream molecular events that regulate matrix and/or cell-surface receptor interactions remain to be identified, recent studies suggest that extracellular proteolysis is a potentially important nexus of regulatory control (Huang et al., 1996; Baranes et al., 1998; Madani et al., 1999; Calabresi et al., 2000; Komai et al., 2000; Pang et al., 2004). Previous work has implicated MMP-9 in forms of protracted hippocampal remodeling accompanying kainic acid-induced epileptogenesis (Zhang et al., 1998; Szklarczyk et al., 2002) and lesion-induced sprouting (Reeves et al., 2003). However, it is unknown whether MMPs are regulated during synaptic plasticity, whether they contribute to changes in synaptic efficacy, and, in so doing, whether they enable memory.

\section{Materials and Methods}

Hippocampal slice preparation, electrophysiology, and reagents. Treatment of all animals conformed to institutional and National Institutes of Health guidelines. Hippocampal slices $(350 \mu \mathrm{m})$ were taken from young (3-6 weeks old) and adult ( $>12$ weeks old) Sprague Dawley rats and 3- to 8-week-old MMP-9 knock-out and wild-type mice (see below) using a McIllwain tissue chopper. Rat and mouse slices were perfused continuously with Ringer's solution containing (in $\mathrm{mm}$ ) $125.0 \mathrm{NaCl}, 2.5 \mathrm{KCl}, 1.3$ $\mathrm{MgSO}_{4}, 1.0 \mathrm{NaH}_{2} \mathrm{PO}_{4}, 26.2 \mathrm{NaHCO}_{3}, 2.5 \mathrm{CaCl}_{2}$, and 11.0 glucose, bubbled with $95 \% \mathrm{O}_{2} / 5 \% \mathrm{CO}_{2}$, during extracellular recordings (electrode solution, $3 \mathrm{M} \mathrm{NaCl}$ ). Slices were maintained for $1-2 \mathrm{~h}$ before establishment of a baseline (20-30 min) of field EPSPs (fEPSPs). The temperature of the recording chamber was maintained at room temperature or at $32 \pm 1^{\circ} \mathrm{C}$ for the duration of the experiments. Electrophysiological and pharmacological experiments using inhibitors and recombinant active enzymes as well as slices prepared for subsequent biochemical analyses (immunoblotting and zymography) were conducted on slices at both temperatures. Results obtained from slices maintained at room temperature or at $32^{\circ} \mathrm{C}$ were identical in all cases. fEPSPs were recorded from the stratum radiatum in area CA1, evoked by stimulation of the Schaffer collateral-commissural afferents every $30 \mathrm{~s}$ with bipolar tungsten electrodes with $100 \mu$ s pulses. Test stimulus intensity was adjusted to obtain fEPSPs with amplitudes that were one-half of the maximal response. The EPSP initial slope (millivolts per milliseconds) was determined from the average waveform of four consecutive responses (Bozdagi et al., 2000). Protein synthesis-dependent late-phase LTP (L-LTP) was induced chemically (cLTP) (20 min bath application of $50 \mu \mathrm{M}$ Sp-cAMPS; BioLog, Hayward, CA) or tetanically (four trains of $100 \mathrm{~Hz}, 1 \mathrm{~s}$ stimulation separated by $5 \mathrm{~min}$ ). An early phase of LTP (E-LTP) was induced with a single train of $100 \mathrm{~Hz}, 1 \mathrm{~s}$ tetanic stimulation. An NMDA receptordependent form of LTD (Dudek and Bear, 1992) was induced by 900 pulses at $1 \mathrm{~Hz}$ for $15 \mathrm{~min}$, whereas a protein synthesis-dependent form of LTD (Huber et al., 2000) was induced by paired-pulse low-frequency stimulation ( $1 \mathrm{~Hz}$ for $15 \mathrm{~min} ; 50 \mathrm{~ms}$ interstimulus interval). Paired-pulse facilitation (PPF) was induced by delivering two stimuli with a 50-200 $\mathrm{ms}$ interstimulus interval. Bath-applied reagents included the following: GM6001 (25 $\mu \mathrm{M}$; Chemicon, Temecula, CA); Inhibitor II (50 $\mu \mathrm{M}$; Calbiochem, La Jolla, CA); recombinant active and pro (inactive) MMP-9 or MMP-2 $(0.5 \mu \mathrm{g} / \mathrm{ml}$ or as indicated in the figures; Calbiochem); echistatin (10 $\mu \mathrm{M}$; Sigma, St. Louis, MO); GRGDSP [arginine-glycine-aspartate (RGD) peptide] and SDGRG (scrambled peptide) (0.5 mm; Sigma); anisomycin (20 $\mu \mathrm{M}$; Sigma); cycloheximide ( $60 \mu \mathrm{M}$; Sigma); and DL-APV (50 $\mu \mathrm{M}$; Tocris, Ellisville, $\mathrm{MO}$ ). For the integrin function-blocking antibody experiments, slices were incubated with antibodies to $\alpha \mathrm{v}, \beta 1$, or a mix- ture of antibodies to $\alpha 3$ plus $\alpha 5$ (all $0.2 \mathrm{mg} / \mathrm{ml}$; Chemicon) or mouse IgG $(0.2 \mathrm{mg} / \mathrm{ml}$; Chemicon) for $3 \mathrm{~h}$ and transferred to the recording chamber. Statistical analyses were performed using ANOVA, in which $p<0.05$ was considered significant.

Immunoblotting. Area CA1 was dissected from stimulated and temporally matched control slices at relevant time points and immediately snap-frozen on dry ice. Fifty microliters of radioimmunoprecipitation assay buffer (50 mu Tris- $\mathrm{HCl}, \mathrm{pH} 8,150 \mathrm{~mm} \mathrm{NaCl}, 0.1 \%$ SDS, $1 \% \mathrm{NP}-40$, $0.5 \%$ sodium deoxycholate, and $1 \times$ Complete Protease Inhibitor Cocktail; Roche Diagnostics, Mannheim, Germany) were added to the slices immediately before homogenization, which was performed at $4^{\circ} \mathrm{C}$ using a motorized Potter-Elvehjem homogenizer. Protein concentrations were determined using Bio-Rad (Hercules, CA) Protein Assay. Reducing sample buffer $(2 \times)(0.125$ M Tris-HCl, pH 6.8, 20\% glycerol, $4 \%$ SDS, and $0.003 \%$ Bromophenol blue) with $5 \% 2$-mercaptoethanol was added to 50 $\mu \mathrm{g}$ of homogenized hippocampal tissue and boiled for $2 \mathrm{~min}$. Samples were loaded on either 7 or 10\% SDS-PAGE gels and electrophoresed. Gels were then transferred onto $0.2 \mu \mathrm{m}$ polyvinylidene difluoride transfer membranes (Immobilon; Millipore, Bedford, MA) using Trans-Blot SD Semi-Dry Transfer Cell (Bio-Rad) at a constant $250 \mathrm{~mA}$ for $2 \mathrm{~h}$. Membranes to be probed with MMP-9 antisera were first blocked overnight in PBS with 5\% nonfat dry milk and 0.1\% Tween 20; those to be probed with MMP-2 antisera were first incubated overnight in Trisbuffered saline (TBS) with 5\% new born calf serum (Invitrogen, Gaithersburg, MD) and $0.05 \%$ Tween 20 . The primary antibody to MMP-2 or MMP-9 (1:500 each; both from Torrey Pines Biolabs, Houston, TX) was diluted in the blocking solutions described above and incubated with the membranes for $2-4 \mathrm{~h}$ at $4^{\circ} \mathrm{C}$. For MMP-9 blots, four $10 \mathrm{~min}$ washes were performed using PBS containing 0.2\% Tween 20; for MMP-2 blots, four 10 min washes were performed with TBS containing $0.05 \%$ Tween 20 . The membranes were then incubated for $1 \mathrm{~h}$ at room temperature with donkey anti-rabbit IgG HRP-conjugated secondary antibody (1:3000; Amersham Biosciences, Piscataway, NJ) diluted in the appropriate blocking solutions. Proteins were visualized using SuperSignal West Pico Lumino/Enhancer Solution (Pierce, Rockford, IL) and developed on X-Omat LS Imaging Film (Eastman Kodak, Rochester, NY). Monoclonal tubulin antibody (1:40,000; Sigma) was used as a loading control on $7 \%$ SDS PAGE gels, and polyclonal glyceraldehyde-3-phosphate dehydrogenase antibody (GAPDH; 1:5000; Trevigen, Gaithersburg, MD) was used as a loading control on 10\% SDS PAGE gels, both diluted in PBS with 5\% nonfat dry milk and $0.1 \%$ Tween 20 . Controls for specificity verified that each antiserum recognized the appropriate recombinant pro and active forms of the MMP against which it was raised and did not cross-react with any form of the inappropriate MMP (supplemental Fig. S2, available at www.jneurosci.org as supplemental material). Densitometric analysis was performed with MetaMorph software (Universal Imaging Corporation, West Chester, PA). For each lane, MMP band intensity was normalized to its loading control band intensity within the same lane; data were expressed as a ratio over the controls and averaged across an individual number of experiments $(n=3-6$ slices per experiment from at least three rats). Data from stimulated slices at each time point were presented as a mean percentage $(+\mathrm{SEM})$ of corresponding data from the temporally matched control slices, where applicable. Statistical analyses were performed with Student's $t$ test, where $p<0.05$ was considered significant.

In vitro gelatin substrate zymography. Hippocampal slices were subjected to cLTP as described. At 0, 15, 30, 60, and 120 min after adenosine$3^{\prime}, 5^{\prime}$-cyclic monophosphorothioate, Sp-isomer (Sp-cAMPS) treatment, slices were snap-frozen on dry ice. At the completion of the last time point, samples were subjected to gelatin zymography according to Zhang and Gottschall (1997). Prepared samples $(10 \mu \mathrm{l})$ were electrophoresed using 5-mm-thick 7\% SDS acrylamide gels containing $0.1 \%$ gelatin. Gels were washed with $2.5 \%$ Triton X-100 and incubated for $16-24 \mathrm{~h}$ at $37^{\circ} \mathrm{C}$. Clear bands of gelatinolysis are visualized against a dark background after the gel is incubated in Coomasie blue and subsequently destained. Recombinant active and pro forms of MMP-9 are run as positive controls and to verify size.

In vivo gelatin zymography. In vivo zymography was performed using a modified protocol from $\mathrm{Oh}$ et al. (1999). Hippocampal slices were sub- 
jected to cLTP as described. Thirty minutes after Sp-cAMPS washout, free-floating slices were incubated with $1 \mu \mathrm{g} / \mu \mathrm{l}$ DQ-gelatin substrate (Molecular Probes, Eugene, OR) for $24 \mathrm{~h}$ at $37^{\circ} \mathrm{C}$, postfixed for $24 \mathrm{~h}$ in $4 \%$ paraformaldehyde (in $0.1 \mathrm{M}$ PBS), and mounted and coverslipped on glass slides. Sections were analyzed on a Zeiss (Thornwood, NY) photomicroscope equipped with appropriate fluorescent filters and a $10 \times$ objective. Images of the stratum radiatum were captured with a Spot digital camera (Diagnostic Instruments, Sterling Heights, MI) using identical image-capture parameters and exposure times for all conditions. Digital images were quantified with MetaMorph software (Universal Imaging), at which a thresholding function was used to capture and quantify numbers of gelatinolytic puncta within each field $(n=3-5$ slices). Data are expressed as the mean (+SEM) of the number of puncta and compared across conditions using one-way ANOVA and Scheffe's post hoc test.

Immunocytochemistry. Procedures and confocal analysis have been described in detail previously (Bozdagi et al., 2000). Hippocampal slices were exposed to Sp-cAMPS and transferred 30-60 min after washout of $\mathrm{Sp}$-cAMPS to $4 \%$ paraformaldehyde. Fixed slices were subsectioned at 50 $\mu \mathrm{m}$ on a vibratome and incubated in rabbit anti-MMP-9 antisera (1: 5000; Torrey Pines Scientific) and one of the following other primary antibodies: mouse anti-microtubule-associated protein-2 (MAP-2; 1:200; Chemicon), mouse anti-glial fibrillary acidic protein (GFAP; 1:200; Chemicon), or a mixture of guinea pig anti-vesicular glutamate transporter (vGlut) 1 and 2 antibodies (1:20,000 and 1:1000, respectively; Chemicon). Primary antibody binding was visualized using speciesappropriate, direct fluorophore-conjugated secondary antibodies (Alexa conjugates, 1:400; The Jackson Laboratory, Germantown, NY). Sections were analyzed by confocal microscopy. Control experiments consisted of omitting the primary antibody.

Synaptic plasticity in MMP-9 knock-out mice. MMP-9 homozygous knock-out mice in a C57BL/6 background were obtained from Dr. Z. Werb (University of California at San Francisco, San Francisco, CA) or from The Jackson Laboratory. These mice were bred to C57/B16NTacF wild-type mice at least two generations. Heterozygous matings were then performed between non-siblings. All mice were group housed and maintained in a $12 \mathrm{~h}$ light/dark cycle with water and food ad libitum. The slice-physiology experiments were performed both in Poland and in New York after obtaining permission from the first Warsaw Animal Experimentation Ethical Committee, or the Mount Sinai Institutional Animal Care and Use Committee, respectively. Hippocampal slices were obtained from 3- to 8-week-old animals and subjected to tetanically induced L-LTP or NMDA receptor-dependent LTD as described above.

Context and cued fear conditioning in MMP-9 knock-out mice. Behavioral experiments were performed in Los Angeles in accordance with the Institutional Animal Care and Use Committee guidelines of the University of California at Los Angeles. Three separate groups of mutants and wild-type littermate controls were subjected to a training session in context " $\mathrm{A}$ " using a $30 \mathrm{~s}$ tone played at $2 \mathrm{~min}$, coterminating with a $2 \mathrm{~s}, 0.75$ $\mathrm{mA}$ constant current scrambled footshock. Minutes $0-2$ during the training session were used to measure baseline freezing. Mice were returned to the same chamber $24 \mathrm{~h}$ later for a 5 min context test. The mice were returned to their home cage for $6 \mathrm{~h}$, at which time cued conditioning was tested in context "B" using a 2 min baseline, followed by a 3 min tone presentation. For training, context test, and cued test, the percentage of time freezing and activity were measured. Automated freezing, activity scores, and activity bursts were calculated using a previously described computer algorithm (Anagnostaras et al., 2000). Briefly, a live, full-screen, 8-bit grayscale video was digitized at $1 \mathrm{~Hz}$ using NIH Image. For every frame, the mean and SD of the density for each conditioning chamber were measured. These values were subsequently converted to activity (arbitrary units) and percentage of freezing scores, such that they highly correlate to experienced human scoring. Suppression of activity ratios was calculated as (activity during test)/(activity during test + baseline activity), which normalizes for hyperactivity or hypoactivity. Oneway ANOVA (genotype) was performed for fear conditioning. A repeated-measures ANOVA was performed on activity bursts.

\section{Results \\ Inhibiting MMP function pharmacologically blocks induction of L-LTP}

To determine whether MMPs function in hippocampal synaptic plasticity, we first blocked MMP activity acutely using a variety of MMP inhibitors and tested the effects of this blockade on LTP at Schaffer collateral-area CA1 synapses in young rat hippocampal slices. Control slices were subjected to a tetanic stimulation protocol that produces both an E-LTP and a subsequently emerging protein synthesis-dependent L-LTP (Bozdagi et al., 2000) (Fig. $1 A$, open circles). In slices that were exposed to a bath-applied pan-MMP inhibitor, GM6001 (25 $\mu \mathrm{M})$, synaptic potentiation is robust and indistinguishable from that elicited in untreated control slices through the first $\sim 60$ min but rapidly diminishes to baseline values thereafter (Fig. 1 $\mathrm{A}$, filled circles) (average percentage of baseline $120 \mathrm{~min}$ after tetanus: GM6001, $101.6 \pm$ $10.1 \%$; control, $200.2 \pm 8.4 \% ; n=6$ rats). It is unknown how many different MMPs are expressed in the hippocampus and thus which ones are potentially blocked by the general inhibitor. However, MMP-9 becomes proteolytically active in the hippocampus several hours after kainic acid-induced seizure activity (Szklarczyk et al., 2002). Therefore, we repeated the experiment using an MMP-2/9 inhibitor (Inhibitor II; $50 \mu \mathrm{M}$ ). Here, we found identical results using the MMP-2/9 inhibitor to those described for the general MMP inhibitor (Fig. $1 B$ ) (Inhibitor II; $101.8 \pm 7.5 \%$ of baseline; $n=6$ rats), indicating that MMP-2 and/or MMP-9 become operative during LTP. Moreover, similar effects on tetanically induced L-LTP were obtained with Inhibitor II in hippocampal slices taken from adult rats (Fig. 1C), indicating that the effects of blocking MMPs on LTP are not limited to a developmental period. A fluorometric enzymatic assay was used to verify that both GM6001 and Inhibitor II blocked $90-100 \%$ of MMP-2 and MMP-9 proteolytic activity at the concentrations used in the slices (supplemental Fig. S1, available at www.jneurosci.org as supplemental material).

The time at which synaptic potentiation declines to baseline in the presence of the acute MMP inhibitors in the rat slices is contemporanous with the transition from E-LTP to L-LTP, suggesting that MMP function is related to the onset of L-LTP. To examine this, we induced L-LTP in the absence of E-LTP using chemical stimulation with Sp-cAMPS (cLTP) (Frey et al., 1993; Bozdagi et al., 2000), a protocol that produces a slowly emerging, protein synthesis-dependent potentiation (Fig. $1 D$, open circles). We found that cLTP in area CA1 is completely abolished by preincubation with the general MMP inhibitor (Fig. $1 D$, filled diamonds) or the MMP-2/9 inhibitor (Fig. $1 D$, filled triangles) (average percentage of baseline $120 \mathrm{~min}$ after Sp-cAMPS: GM6001, $96.3 \pm 9.4 \%$; Inhibitor II, $105.2 \pm 8.7 \%$; control, $179 \pm 8.5 \%$; $n=6$ rats each group). To determine whether MMP activity is required to maintain L-LTP once established, we added MMP2/9 inhibitor to potentiated slices $60-90 \mathrm{~min}$ after induction of L-LTP by chemical or tetanic stimulation. There is no effect on synaptic potentiation once established, using either LTP stimulation method, indicating that MMP activity is required for induction but not maintenance of L-LTP (Fig. $1 E$ ). We verified that these MMP inhibitors had no effects on basal synaptic transmission because stimulus-response curves in inhibitor-incubated slices are identical to those elicited from untreated control slices (data not shown). Together, these results indicate that MMP-9, and possibly also MMP-2, is required for the induction of L-LTP specifically. 

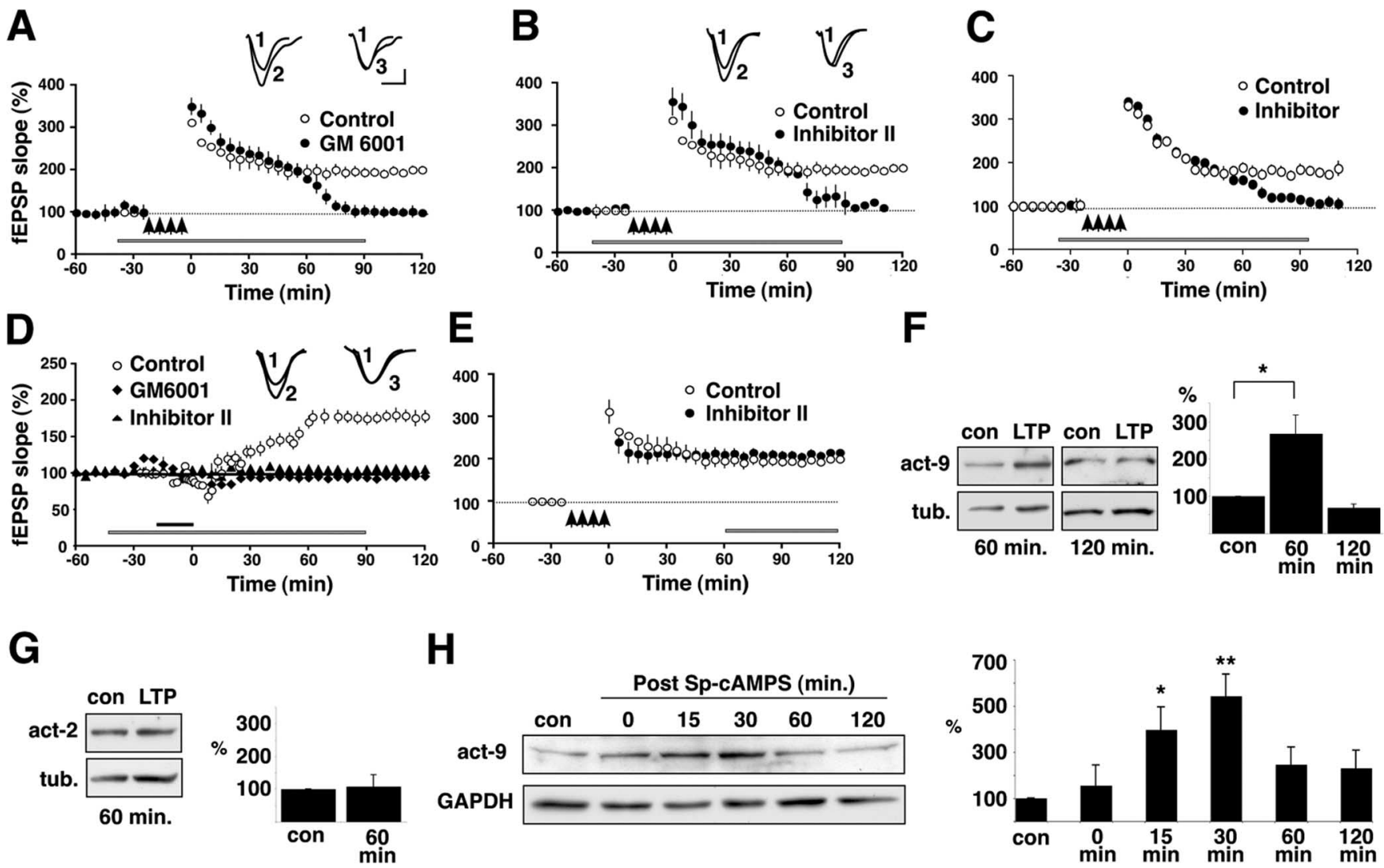

H

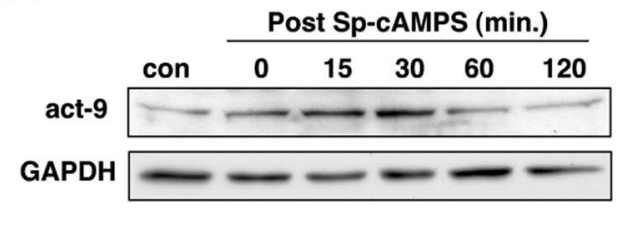

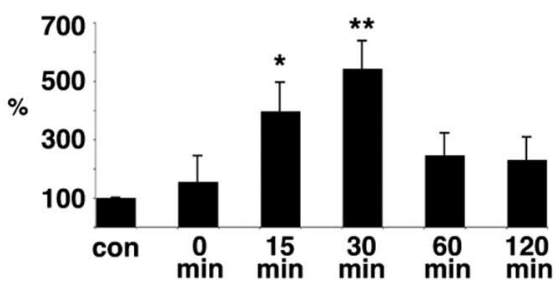

Figure 1. MMP-9 is required for, and upregulated during, L-LTP in area CA1.A, Young rat hippocampal slices were subjected to an L-LTP-inducing tetanic stimulation protocol (arrows; four trains of $100 \mathrm{~Hz}, 1 \mathrm{~s}$ stimulation separated by $5 \mathrm{~min}$ ), which produces both an E-LTP and a long-lasting L-LTP (open circles). In contrast, in the presence of GM6001 (25 $\mu \mathrm{M})$, a broad-spectrum MMP inhibitor (bar), normal E-LTP is elicited but L-LTP is abolished, as shown by the return of the trace to baseline levels between 60 and $90 \mathrm{~min}$ (filled circles; $n=6$ rats). Inset, Representative EPSP traces were recorded before tetanus (1), $90 \mathrm{~min}$ after tetanus (2), and $90 \mathrm{~min}$ after tetanus in the presence of GM6001 (3). B, Young rat hippocampal slices exposed to an MMP-2/9 inhibitor (Inhibitor ll; $50 \mu \mathrm{M}$ ) and subjected to L-LTP-inducing tetanic stimulation also show normal E-LTP but abolishment of L-LTP (filled circles). Other conventions are as in $A$. Inset, Representative EPSP traces were recorded before tetanus (1), 90 min after tetanus (2), and 90 min after tetanus in the presence of Inhibitor II (3). C, Hippocampal slices from adult rats exposed to Inhibitor II (bar) and subjected to L-LTP-inducing tetanic stimulation (arrows) also show a normal E-LTP (filled circles) compared with control slices (open circles), but L-LTP is abolished. This pattern is identical to that observed in young rat slices (compare with Fig. 1A, B). D, Rat hippocampal slices bath exposed to Sp-CAMPS (20 min; solid bar) show a robust, slowly developing cLTP (open circles). In contrast, CLTP is abolished in slices coincubated in Sp-cAMPS and either GM6001 ( $25 \mu \mathrm{m}$; filled diamonds) or Inhibitor II (50 $\mu \mathrm{m}$; filled triangles; duration of inhibitor shown by gray bar). Inset, Representative EPSP traces were recorded before Sp-CAMPS application (1), $90 \mathrm{~min}$ after Sp-cAMPS application (2), and $90 \mathrm{~min}$ after Sp-CAMPS in the presence of Inhibitor II (3). E, Exposing rat hippocampal slices to the MMP-2/9 inhibitor (bar) after tetanically induced L-LTP is established has no effect on maintenance of L-LTP (filled circles); the potentiation in treated slices is indistinguishable from that in untreated control slices (open circles). $\boldsymbol{F}$, Pairs of representative immunoblots of homogenates from area CA1 frozen $60 \mathrm{~min}$ (left pair) or $120 \mathrm{~min}$ (right pair) after control or L-LTP-inducing tetanic stimulation. Membranes were probed with antibodies that recognize the active form of MMP-9 (act-9) or tubulin. The summary graph (right) shows the mean band intensity normalized to corresponding time-matched controls. There is a significant elevation in the levels of the active form of MMP- 9 at 60 min after LTP stimulation $\left({ }^{*} p<0.03 ; n=3\right)$, but levels return to control values by 120 min. $\mathbf{G}$, Representative immunoblot of homogenates from area CA1 frozen $60 \mathrm{~min}$ after control or L-LTP-inducing tetanic stimulation. Membranes were probed with antibodies that recognize the active form of MMP-2 (act-2) or tubulin. The summary graph shows that there are no changes in the levels of active MMP-2 at this time point after LTP stimulation $(n=3)$, nor are there any changes in the levels of MMP-2 at other times up to 120 min after stimulation (other time points not shown). $\boldsymbol{H}$, Representative immunoblot of homogenates from area CA1 subjected to CLTP by brief bath exposure to Sp-cAMPS and frozen at the times indicated after washout of Sp-cAMPS. Membranes were probed with antibodies recognizing the active form of MMP-9 or GAPDH. The summary graph ( $n=3$ per time point) shows that levels of the active form of MMP- 9 increase by $15 \mathrm{~min}$ after washout of Sp-CAMPS, peak by $30 \mathrm{~min}$, and decline toward baseline thereafter through 120 min. ${ }^{*} p<$ $0.05 ; * * 0.005$. Error bars indicate SEM. Calibration: $10 \mathrm{~ms}, 0.2 \mathrm{mV}$. con, Control; tub., tubulin.

Levels and proteolytic activity of MMP-9 but not MMP-2 increase in response to L-LTP induction

The functional requirement for MMP-9 and/or MMP-2 in L-LTP induction suggests that the activity of one or both of these MMPs is upregulated just before or during L-LTP onset. To determine which MMP is involved, we first immunoblotted potentiated slices at various times after LTP stimulation using MMP-2- or MMP-9-specific antisera that recognize both pro (inactive) and active forms that can be easily distinguished by differences in their molecular mass (supplemental Fig. S2, available at www.jneurosci.org as supplemental material). Immunoblot analyses of area CA1 homogenates prepared from slices in which LTP was induced tetanically show that levels of the active form of MMP-9 are significantly elevated by $60 \mathrm{~min}$ after stimulus compared with temporally matched control slices and return to control values by $120 \mathrm{~min}$ after tetanus (Fig. $1 F$ ). In contrast, levels of active MMP-2 are unchanged in tetanically stimulated slices at $60 \mathrm{~min}$ after stimulation (Fig. $1 G$ ) and at other time points tested between 0 and 120 min after stimulation (data not shown). These data suggest that proteolytic activity of MMP-9, but not MMP-2, is required for induction of L-LTP. The lack of a response of MMP-2 to synaptic plasticity is similar to previous studies showing that MMP-9, but not MMP-2, becomes active in response to $\mathrm{KCl}$ - or kainic acid-induced seizure activity (Szklarczyk et al., 2002; Jourquin et al., 2003). Thus, MMP-9 seems to be the relevant MMP, the function of which is required for L-LTP.

The rise in levels of active MMP-9 by 60 min after tetanic stimulation is consistent with a role in the induction of L-LTP. To 
A
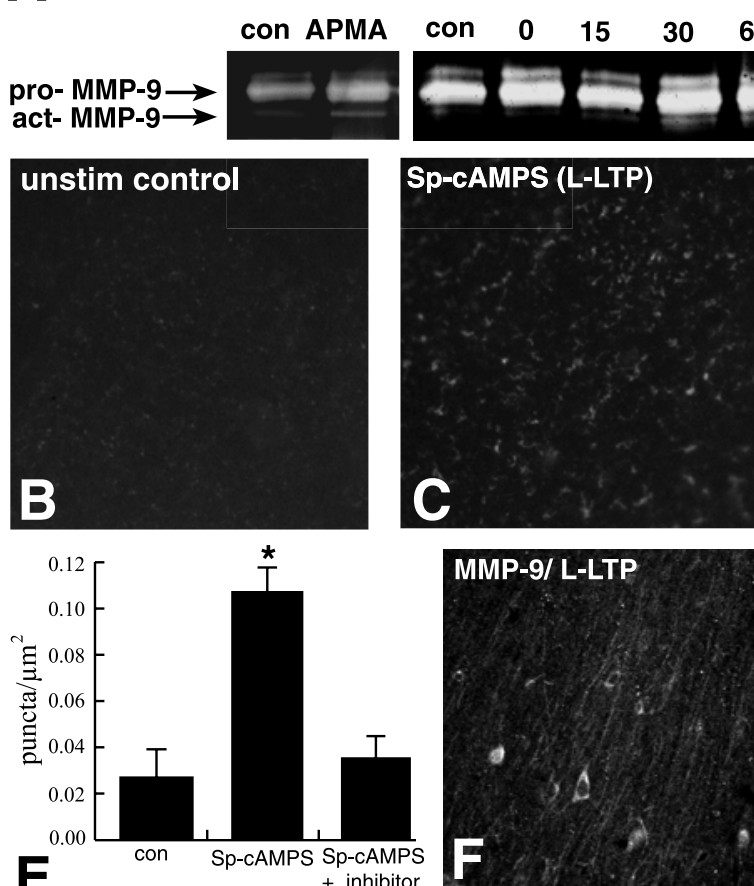

D
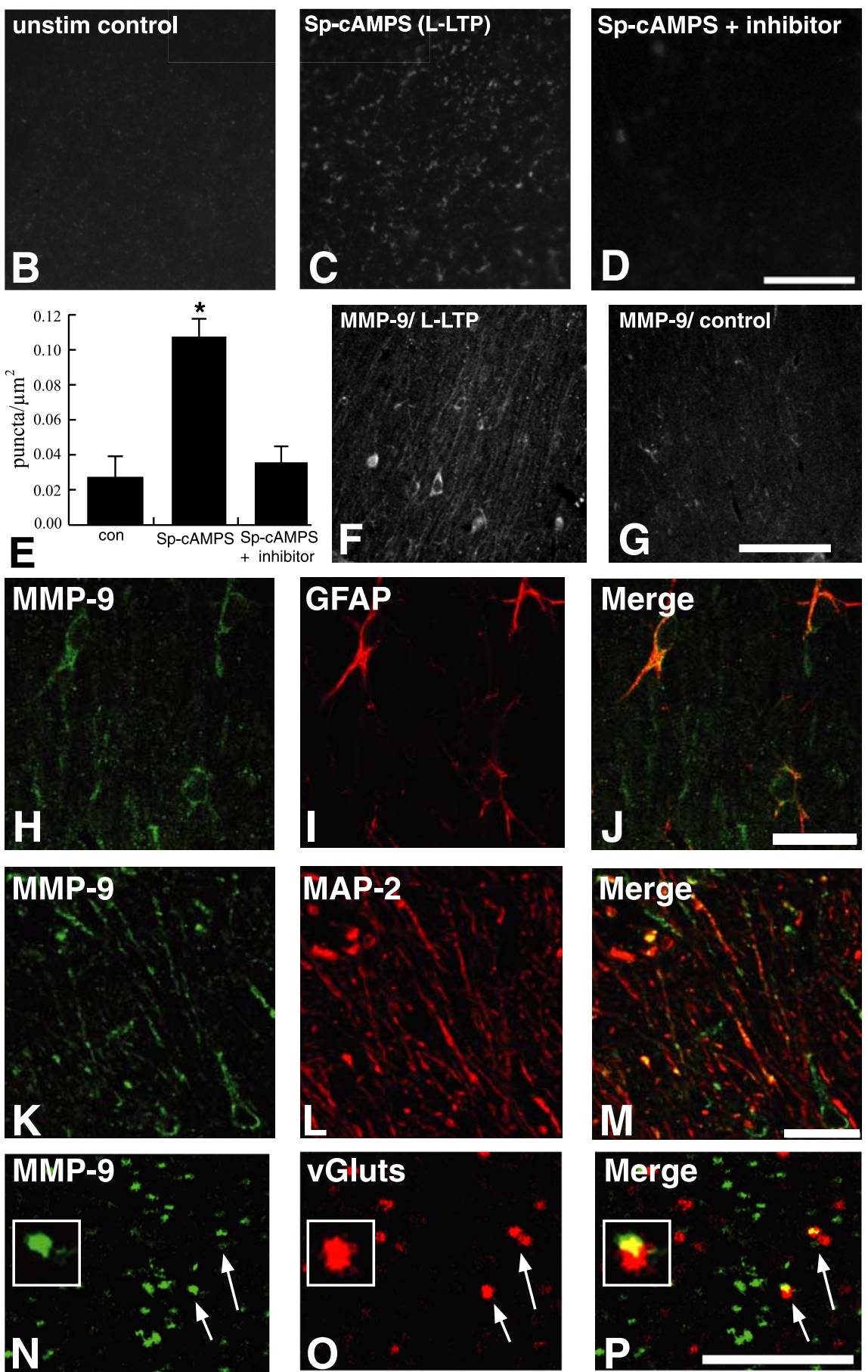
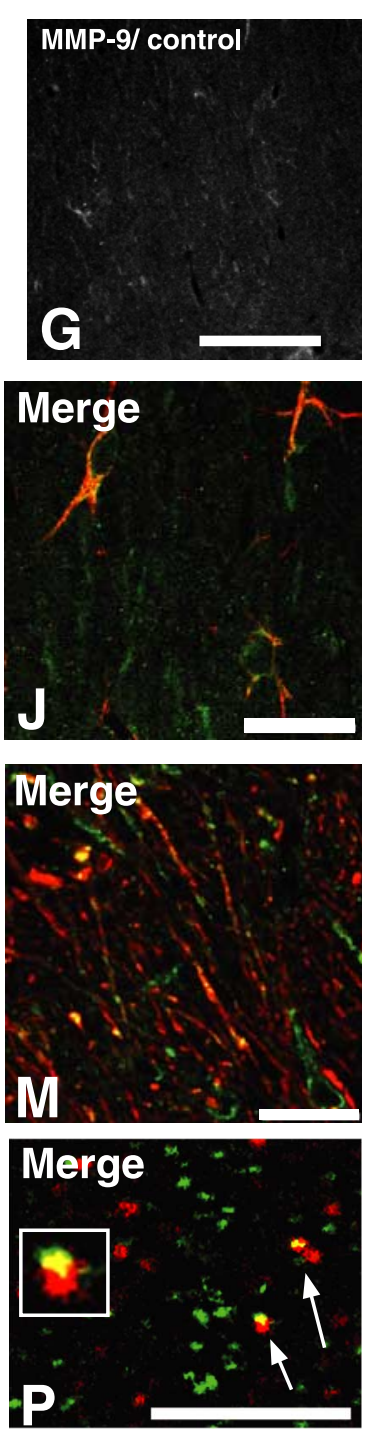

Figure 2. Proteolytic activity and localization of MMP-9 during L-LTP. A, In vitro gelatin zymography of homogenates from control and Sp-CAMPS-treated slices. Low-levels of both pro and active (act) forms of MMP-9 are visible in control sections; enzymatic activity of the active form of MMP-9 increases in CLTP slices frozen 30 and 60 min after Sp-cAMPS washout. Identity of the bands was determined by comigration with those that appear after incubation of homogenates with APMA, an organomercurial compound that induces some autoactivation of MMPs. $\boldsymbol{B}-\boldsymbol{D}$, Representative confocal images of hippocampal slices processed for in vivo zymography. A significant increase in the numbers of fluorescent, gelatinolytic puncta are evident in CLTP slices frozen 30 min after Sp-cAMPS washout ( $\boldsymbol{C}$ compared with control slices $(\boldsymbol{B})$. The increase in the numbers of L-LTP-associated gelatinolytic puncta was blocked by coincubating slices with MMP inhibitors (Inhibitor II is shown; $\boldsymbol{D}$ ). $\boldsymbol{E}$, Summary graph showing quantification of data represented in $\boldsymbol{B}-\boldsymbol{D}$, verifying a significant increase in the numbers of gelatinolytic puncta in CLTP slices $(p<0.02$ relative to control) that was blocked by MMP inhibitors $(n=5) . \boldsymbol{F}, \mathbf{G}$, Confocal images showing immunofluorescent

examine this further, we performed immunoblot time-course analysis of slices exposed briefly to Sp-cAMPS to induce L-LTP selectively. Figure $1 H$ shows that levels of active MMP-9 increase slightly after the $20 \mathrm{~min}$ exposure to Sp-cAMPS compared with untreated controls, peak at 30 min after washout, and decline toward baseline thereafter through $120 \mathrm{~min}$. The sustained elevation of MMP-9 levels with chemical induction compared with the return to baseline levels at 120 min seen with tetanic induction may reflect the fact that the bath-applied, membrane-permeable Sp-cAMPS affects many more, perhaps all, cells in the slice and may therefore be a "stronger" or more persistent stimulus.

To verify the increase in levels of the active form with L-LTP and to confirm that MMP-9 was proteolytically active, we subjected stimulated and control slices to gelatin zymography. Hippocampal homogenates were prepared from slices taken at variable times after washout of Sp-cAMPS. In unstimulated control sections, pro-MMP-9 is evident, but only a very faint band of the active form of MMP-9 is visible (Fig. 2A). However, at 30 and 60 min after washout, the gelatinolytic activity of the active form of MMP-9 is elevated compared with controls, indicating that MMP-9 becomes proteolytically active in response to L-LTP induction (Fig. 2A). We further confirmed this using in vivo zymography, which additionally reveals the anatomical localiza-

\section{$\leftarrow$}

localization of MMP-9 in area CA1 stratum radiatum in slices taken 30 min after Sp-CAMPS washout $(\boldsymbol{F})$ or in control slices $(\boldsymbol{G})$. There is a greater number and intensity of immunoreactive profiles evident in the CLTP slices compared with control slices. $\boldsymbol{H}-\boldsymbol{J}$, Confocal images of area CA1 stratum radiatum in cLTP slices immunolabeled 30 min after Sp-CAMPS washout showing immunoreactivity for MMP-9 ( $\boldsymbol{H}$; green) and for the astrocyte marker GFAP (I; red) separately and as an overlay $(J)$, in which codistribution is evident as indicated by regions of overlap of the two channels (yellow) in the merged image. $K-M$, Confocal images of area CA1 stratum radiatum in CLTP slices immunolabeled $30 \mathrm{~min}$ after Sp-CAMPS washout showing immunoreactivity for MMP-9 ( $\boldsymbol{K}$; green) and for the dendritic marker MAP-2 ( $\boldsymbol{L}$; red) separately and as an overlay $(\boldsymbol{M})$, in which codistribution is evident as indicated by regions of overlap of the two channels (yellow) in the merged image. $\boldsymbol{N}-\boldsymbol{P}$, High-magnification confocal images of the stratum radiatum neuropil from CLTP slices immunolabeled $30 \mathrm{~min}$ after Sp-cAMPS washout. The images show numerous punctate profiles immunoreactive for MMP-9 ( $\boldsymbol{N}$; green, arrows) and for the synaptic marker vGluts ( $\mathbf{0}$; red, arrows), shown separately and as on the overlay $(\boldsymbol{P})$, in which synaptic codistribution is evident as indicated by punctate regions of overlap of the two channels (yellow, arrows, and inset) in the merged image. Scale bars: $\boldsymbol{D}, 50 \mu \mathrm{m} ; \boldsymbol{G}, 100 \mu \mathrm{m} ; \boldsymbol{J}, \boldsymbol{M}, 25$ $\mu \mathrm{m} ; \boldsymbol{P}, 5 \mu \mathrm{m}$. con, Control. 
tion of such proteolytic activity. In untreated control sections, faint fluorescent puncta representing gelatinolytic activity are evident throughout synaptic regions of area CA1 (stratum radiatum) (Fig. 2 B). At 30-60 min after Sp-cAMPS washout, the intensity and number of such gelatinolytic puncta increase significantly (Fig. 2C,E). To confirm that such proteolytic activity is mediated by MMPs, a set of slices was coincubated in Sp-cAMPS and either the general MMP inhibitor (GM6001) or MMP-2/9 inhibitor (Inhibitor II). Both inhibitors completely abrogate the SpcAMPS-induced increase in the number of gelatinolytic puncta in the stratum radiatum (Fig. 2D,E). Control experiments confirmed that neither levels of pro- or active-MMP-9 nor proteolytic activity increase over time in response to tissue slicing (supplemental Fig. S3, available at www.jneurosci.org as supplemental material). Thus, these data show that MMP-9 becomes proteolytically active during the onset of L-LTP within the neuropil of area CA1 stratum radiatum, the region containing the potentiated synapses.

To identify what cellular elements were associated with MMP-9 in stimulated slices, we paraformaldehye-fixed slices after induction of cLTP and immunolabeled for dendritic, glial, and synaptic molecular markers. A significantly greater number of MMP-9-immunoreactive profiles was evident throughout the synaptic and dendritic regions (stratum radiatum) of area CA1 in the potentiated slices (Fig. $2 F$ ) compared with those present in control slices (Fig. 2G). Double immunolabeling revealed that such MMP-9-immunopositive profiles in the potentiated slices include GFAP-immunopositive astrocytes (Fig. 2H-J), MAP-2immunopositive dendrites (Fig. $2 K-M$ ), and vGlut-immunopositive synapses (Fig. $2 \mathrm{~N}-\mathrm{P}$ ). Together, these results demonstrate that MMP-9 becomes proteolytically active during induction of L-LTP and associates with glial, dendritic, and synaptic profiles within the potentiated neuropil.

\section{MMP-9 is not required for, nor regulated by, other forms of synaptic plasticity}

To verify a role for MMP-9 in induction of L-LTP selectively, we tested the effects of MMP inhibitors on other forms of both shortand long-lasting synaptic plasticity. We first tested the effects of inhibitors on E-LTP using a weaker tetanic stimulation protocol (a single train of $100 \mathrm{~Hz}, 1 \mathrm{~s}$ stimulation) than the one used above to induce L-LTP. There is no effect on E-LTP in the presence of the MMP-2/9 inhibitor (Fig. $3 A)(p=0.44 ; n=4$ rats). Consistent with this, immunoblot analyses show that there are no changes in levels of the active form of MMP-9 with stimuli that induce E-LTP compared with temporally matched control slices (Fig. 3A, inset). Similarly, there are no effects of MMP inhibitors on PPF (data not shown), another form of short-term plasticity. We next examined the effects of MMP inhibitors on two different forms of electrically induced LTD of area CA1 synaptic strength, one of which requires NMDA receptors but not protein synthesis
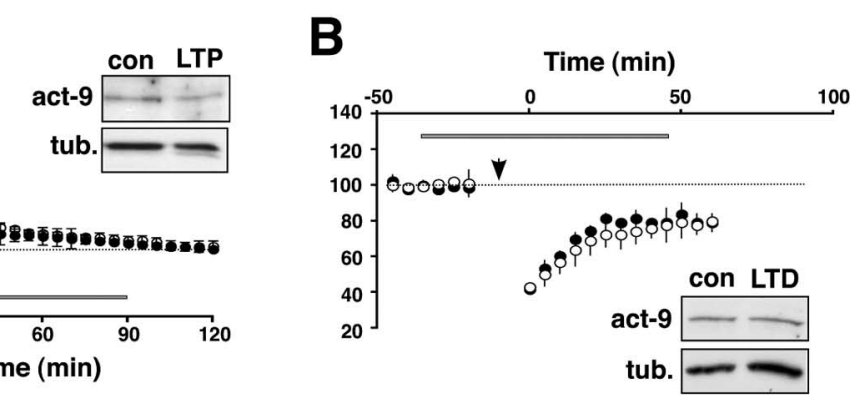

00

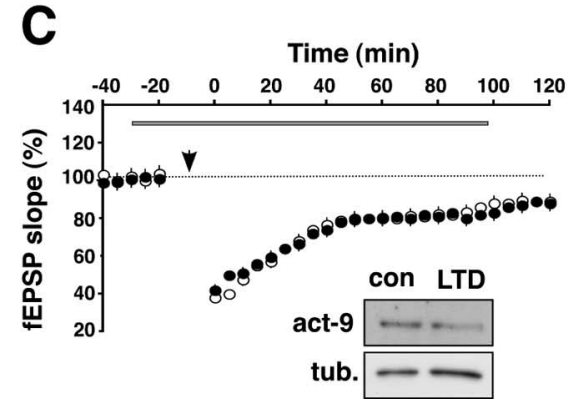

Figure 3. MMP-9 has no role in, nor is regulated during, other forms of synaptic plasticity. $A$, Rat hippocampal slices subjected to a weak tetanic stimulation protocol that produces E-LTP (arrow; a single train of $100 \mathrm{~Hz}, 1 \mathrm{~s}$ tetanic stimulation; open circles). es bath exposed to the MMP-2/9 inhibitor (Inhibitor II, $50 \mu \mathrm{m}$; filled circles) exhibit E-LTP that is indistinguishable from that (hices, indicating that MMP-9 has no role in this form of plasticity. Consistent with this, the inset shows

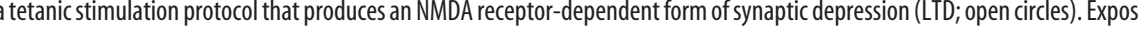
of LTD. Consistent with this, the inset shows a representative immunoblot of area CA1 homogenates frozen 60 min after stimulation; levels of the active form of MMP-9 are unchanged compared with control slices. con, Control; act, active form; tub., tubulin.

(Dudek and Bear, 1992) and the other that requires metabotropic glutamate receptors and protein synthesis (Huber et al., 2000). Neither form of LTD was affected by MMP inhibitors (Fig. 3 B, C) ( $p=0.43$ and $p=0.46 ; n=4$ rats for each group). Consistent with the lack of a functional role in LTD, immunoblots show that levels of the active form of MMP-9 are unaffected by either LTDstimulation protocol (Fig. $3 B, C$, insets). Thus, the lack of any apparent requirement for MMP-9 in E-LTP, decremental potentiation, or LTD is consistent with the lack of any stimulusinduced increase in MMP protein levels during these same forms of synaptic plasticity. These data indicate that synaptic activity or modification of synaptic strength per se is insufficient for regulating levels of active MMP-9. Instead, MMP-9 levels increase only in response to stimuli that induce L-LTP.

\section{Increase in levels of MMP-9 requires NMDA receptors and protein synthesis}

We next investigated some of the components of the signaling cascade that contribute to the L-LTP-associated increase in MMP-9 levels and activity. We first tested requirements for NMDA receptor activation, because NMDA receptors are known to be required for induction of tetanic or chemical LTP (Collingridge and Bliss, 1987; Otmakhov et al., 2004). Slices were exposed to the NMDA receptor antagonist APV during L-LTPinducing tetanic stimulation. Immunoblot analyses show that APV completely blocks the L-LTP-associated increase in MMP-9 protein levels compared with slices incubated in APV alone or 

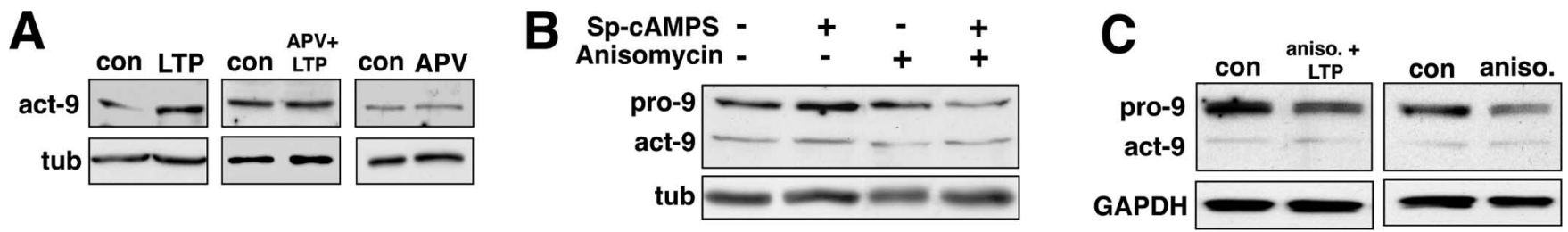

Figure 4. Increase in levels of MMP-9 during L-LTP requires NMDA receptor activation and protein synthesis. A, Representative pairs of immunoblots of area $C A 1$ homogenates frozen 60 min after control stimulation, after L-LTP tetanic stimulation (LTP), after L-LTP tetanic stimulation in the presence of the NMDA receptor antagonist APV (APV+LTP), or after control stimulation in the presence of APV alone (APV). Membranes were probed for the active form of MMP-9 or tubulin. The increase in levels of active MMP-9 evident 60 min after post-LTP tetanic stimulation (left) is blocked in tetanically stimulated slices incubated with APV (middle). Incubation in APV alone, without L-LTP stimulation, has no effect on MMP-9 levels (right). Blots shown are representative of results from three to six slices from at least three rats. $\boldsymbol{B}$, Representative immunoblots of area CA1 homogenates frozen $30 \mathrm{~min}$ after Sp-CAMPS washout used to induce cLTP. Membranes were probed with the MMP-9 antibody; both pro and active forms of MMP-9 are shown. The increase in levels of both forms of MMP-9 evident in the CLTP slices is blocked by incubating slices in the protein synthesis inhibitor anisomycin $(20 \mu \mathrm{m})$. The blots shown are representative results from three to six slices from at least three rats. C, Pairs of representative immunoblots of area CA1 homogenates frozen $60 \mathrm{~min}$ after receiving control stimulation, tetanic L-LTP-stimulation in the presence of anisomycin, or control stimulation plus anisomycin alone. Membranes were probed with the MMP-9 antibody or an antibody to GAPDH. Both pro and active forms of MMP-9 are shown. The L-LTP-associated increase in levels of MMP-9 induced tetanically is blocked by anisomycin. The blots shown are representative of results from three to six slices from at least three rats. con, Control; act, active form; tub., tubulin; aniso., anisomycin.

untreated control slices (Fig. 4A). These data indicate that NMDA receptor activation is required for the L-LTP-associated increase in MMP-9 protein levels.

L-LTP also depends on de novo protein synthesis (Frey et al., 1988), so we incubated slices with the protein synthesis inhibitor anisomycin $(20 \mu \mathrm{M})$ in the presence of Sp-cAMPS or during tetanic stimulation. Immunoblot analyses show that blocking protein synthesis with anisomycin prevents the L-LTP-induced increase in levels of both pro and active forms of MMP-9, regardless of whether L-LTP is induced chemically (Fig. $4 B$ ) or tetanically (Fig. 4C). Identical results were obtained from slices in which protein synthesis was blocked with cycloheximide (data not shown).

\section{Proteolytically active MMP-9 produces a slow integrin-dependent potentiation}

We next investigated the consequences of MMP-9 proteolytic activity on synaptic function by exposing slices to recombinantactive MMP-9 and recording fEPSPs in the stratum radiatum. Brief bath application of MMP-9 $(1 \mu \mathrm{g} / \mathrm{ml})$ produces a consistent increase in fEPSP slope that first appears $\sim 30 \mathrm{~min}$ after washout of the active enzyme, yielding an average potentiation of $155 \pm$ $2.9 \%$ by $150 \mathrm{~min}$ (Fig. $5 A)(n=4$ rats). Such potentiation by active MMP-9 was dose dependent; bath application of 0.5 or 0.1 $\mu \mathrm{g} / \mathrm{ml}$ active MMP-9 produced $139 \pm 3.0 \%$ or $0 \%$ increase, respectively, at $150 \mathrm{~min}$ after washout (Fig. $5 \mathrm{~A}$ ). The potentiation of fEPSPs is not caused by a nonspecific increase in excitability because the amplitude of the fiber volleys is not significantly different than untreated control slices $(107 \pm 5.1 \%$ of control values at 150 min after MMP-9 washout; $n=4 ; p>0.5)$. We verified that the slow potentiation reflected MMP-9 activity by coincubating slices with the MMP-2/9 inhibitor. In these slices, no potentiation emerged over the 120 min recording period (Fig. 5B). Additionally, no potentiation was observed when slices were exposed to the inactive pro form of MMP-9 (Fig. 5B). As further verification of specificity in the potentiating effects of active MMP-9, we exposed slices to recombinant-active MMP-2. However, no potentiation was evident over a range of concentrations (from 0.5 to 5.0 $\mu \mathrm{g} / \mathrm{ml}$ ) (Fig. 5 C). Such a lack of effect of active MMP-2 is consistent with a lack of regulation of MMP-2 levels during LTP induction as shown above.

It has been reported previously that hippocampal slices exposed to integrin ligands bearing the RGD-binding motif exhibit a slowly emerging potentiation that is strikingly similar to that shown above resulting from exposure to active MMP-9 (Kramar et al., 2003). Therefore, we hypothesized that MMP-9-induced potentiation might be mediated through activation of RGDbinding integrin receptors. We first tested this by preincubating slices in echistatin, a potent disintegrin, and bath-applying active MMP-9 while recording fEPSPs from area CA1. In these slices, no potentiation emerged over the $150 \mathrm{~min}$ recording period (Fig. $5 D$, filled diamonds). The disintegrin was only effective when present during the induction of the MMP-9-induced potentiation, because application of echistatin $\sim 30$ min after potentiation was established had no effect (Fig. $5 D$, open circles). To test further the specificity of integrin activation in MMP-9-induced potentiation, we repeated these experiments using two other, structurally distinct types of integrin antagonists. In the first set of experiments, we preincubated slices with a synthetic RGD peptide (GRGDSP) or a scrambled peptide (SDGRG) during brief application of active MMP-9 (Fig. 5E). No potentiation was evident in the RGD-treated slices during the 150 min recording period (Fig. 5E, filled diamonds); in contrast, robust potentiation was evident in the slices exposed to the scrambled peptide (Fig. $5 E$, open squares). In the second set of experiments, we preincubated slices in functionblocking integrin subunit antibodies or antibody combinations that have been used previously to impair LTP maintenance (Chun et al., 2001). No potentiation was evident in slices preincubated with antibodies to $\alpha 3$ and $\alpha 5$, nor was potentiation evident in slices preincubated with antibodies to $\alpha \mathrm{v}$ or $\beta 1$ (Fig. $5 F$ ). In contrast, a robust potentiation was evident in slices preincubated in mouse IgG (data not shown). Together, these data suggest strongly that activated MMPs induce a slow synaptic potentiation mediated by RGDbinding integrin receptors.

\section{MMP-9 knock-out mice exhibit impairments in LTP and hippocampal-dependent associative learning}

To verify further a functional role for MMP-9 in area CA1 LTP, we applied L-LTP-inducing tetanic stimulation to the Schaffer collaterals in slices taken from mice carrying a homozygous disruption of the MMP-9 gene (Vu et al., 1998). The age range of the mice from which slices were taken for these experiments was comparable to that of the rat slices described above. Here, we found that the magnitude of LTP is significantly smaller and the duration is shorter in slices from MMP-9 null-mice compared with a robust, long-lasting potentiation of synaptic transmission in slices from wild-type mice (Fig. 6A). This pattern of LTP deficit was clearly different than that described above for the acute pharmacological blockade of MMP-9 in the rat slices. To investigate potential explanations for such differences, we first ruled out overt differences between wild-type and null-mutant slices in basic prop- 
erties of synaptic transmission, because there were no apparent differences in the stimulation/response properties of fEPSPs at stimulus intensities of 2-20 V (supplemental Fig. S4A, available at www.jneurosci. org as supplemental material). We also ruled out the possibility that null-mutant slices exhibited general impairments in all forms of synaptic plasticity. There were no differences between wild-type and null-mutant slices in NMDA receptor-dependent LTD (Fig. $6 B)(p=0.3 ; n=3$ mice per genotype), nor in PPF, a short-term form of plasticity (supplemental Fig. S4B, available at www.jneurosci.org as supplemental material). These data are consistent with results using the pharmacological blockers in rat slices showing a lack of a role of MMP-9 in these forms of short- and long-term plasticity. We next ruled out differences between rat and wild-type mouse slices in the effects of the pharmacological blockers on LTP. In wild-type mouse slices that were exposed to Inhibitor II ( $50 \mu \mathrm{M})$, L-LTP tetanic stimulation produced synaptic potentiation that was robust and indistinguishable from that elicited in untreated wild-type slices through the first $\sim 60 \mathrm{~min}$ but then declined to baseline thereafter, similar to that described for the rat slices (Fig. 6C). These data show that the pharmacological inhibitors affect LTP similarly in rats and mice. We also ruled out potentially spurious effects of the pharmacological inhibitors in that null-mutant slices exposed to the MMP inhibitors exhibited deficient LTP that was indistinguishable from that elicited in untreated null-mutant slices (Fig. 6D). These data indicate that genetic deletion of MMP-9 occludes the effects of MMP-9 inhibitors on LTP. Finally, we tested whether restoring MMP-9 activity to the null-mutant slices could rescue the deficient LTP by pairing the same L-LTP tetanic stimulation protocol used above in the mutant slices with bath application of recombinant active MMP-9. Here, we found that LTP was completely restored in both magnitude and duration, appearing indistinguishable from that elicited in wild-type mice (Fig. $6 E)(n=2-4$ mice per genotype). Together, these data from null-mutant slices are consistent with those from the acute pharmacological experiments in rat slices in showing that MMP-9 plays a significant role in regulating LTP but not other forms of synaptic plasticity. Additional deficits in LTP are apparent in the null-mutant slices; the mechanisms underlying these additional deficits remain to be elucidated.

The requirement for MMP-9 activation during LTP shown in the slice experiments suggests that MMP-9 proteolytic activity is a fundamental component of behaviorally relevant associative processes of the kind thought to be based on enduring forms of synaptic plasticity such as LTP. To investigate the functional requirements for MMP-9 in hippocampus-dependent associative learning, MMP-9 $9^{-1-}$ mutant mice were subjected to context and cued fear conditioning. In this task, mice learn to associate a mild
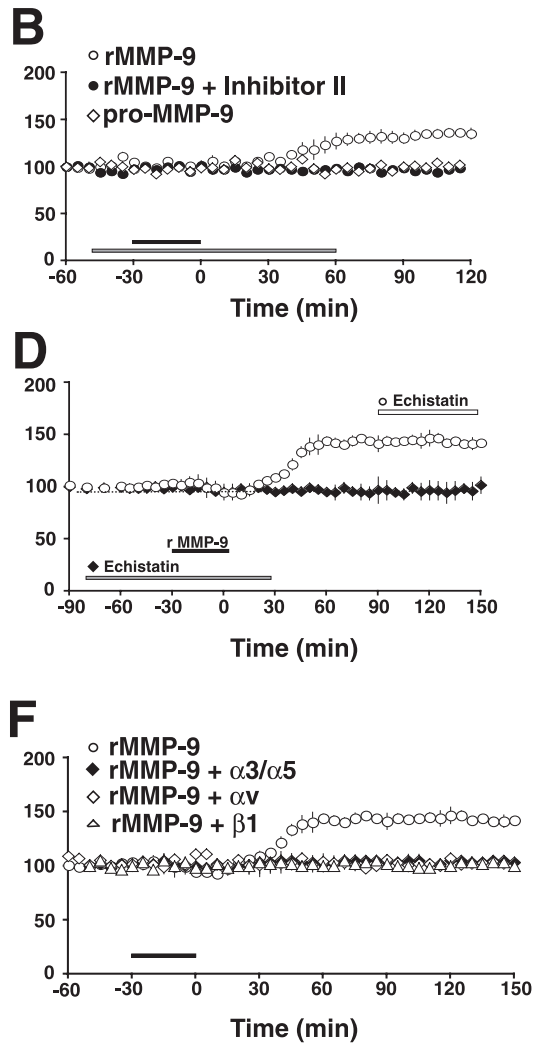

Figure 5. Active MMP-9 induces a slow integrin-dependent potentiation in area CA1. $\boldsymbol{A}$, Rat hippocampal slices were exposed $=3-4$ rats per condition). Error bars indicate SEM. Inset, Representative EPSP traces were recorded before (1) and 90 min afte circles, durationshown by recombinant active MMP-9-induced potentiation (open circles) is blocked by coincubating slices with echistatin (10 $\mu$ M) a snake open triangles) or antibody combinations ( $\alpha 3 / \alpha 5$; filled diamonds) also blocks the MMP-9-induced potentiation $(n=3-4$ rats per group). All antibody concentrations are $0.2 \mathrm{mg} / \mathrm{ml}$. rMMP-9, Recombinant active MMP-9.

footshock with a specific training context and a specific tone. When the mice are later re-exposed to either the context or tone, they reduce their overall activity and exhibit freezing behavior, defined as a cessation of all movement, except for respiration. Such pavlovian fear conditioning to the training context is dependent on both hippocampus and amygdala function, whereas fear conditioning to the cue (tone) requires the amygdala but is hippocampus independent (Kim and Fanselow, 1992). Mice were trained in context A using a $30 \mathrm{~s}$ tone coterminating with a $2 \mathrm{~s}, 0.75 \mathrm{~mA}$ shock. During the training session, the mutant mice displayed baseline activity that was similar to that displayed by their wild-type littermate controls (Fig. $6 F$ ). When the mice were tested at $24 \mathrm{~h}$ in the same context A for hippocampus-dependent context conditioning, the MMP- $9^{-1-}$ mutant mice displayed significantly reduced memory (Fig. $6 G$ ). In contrast, when tested at 

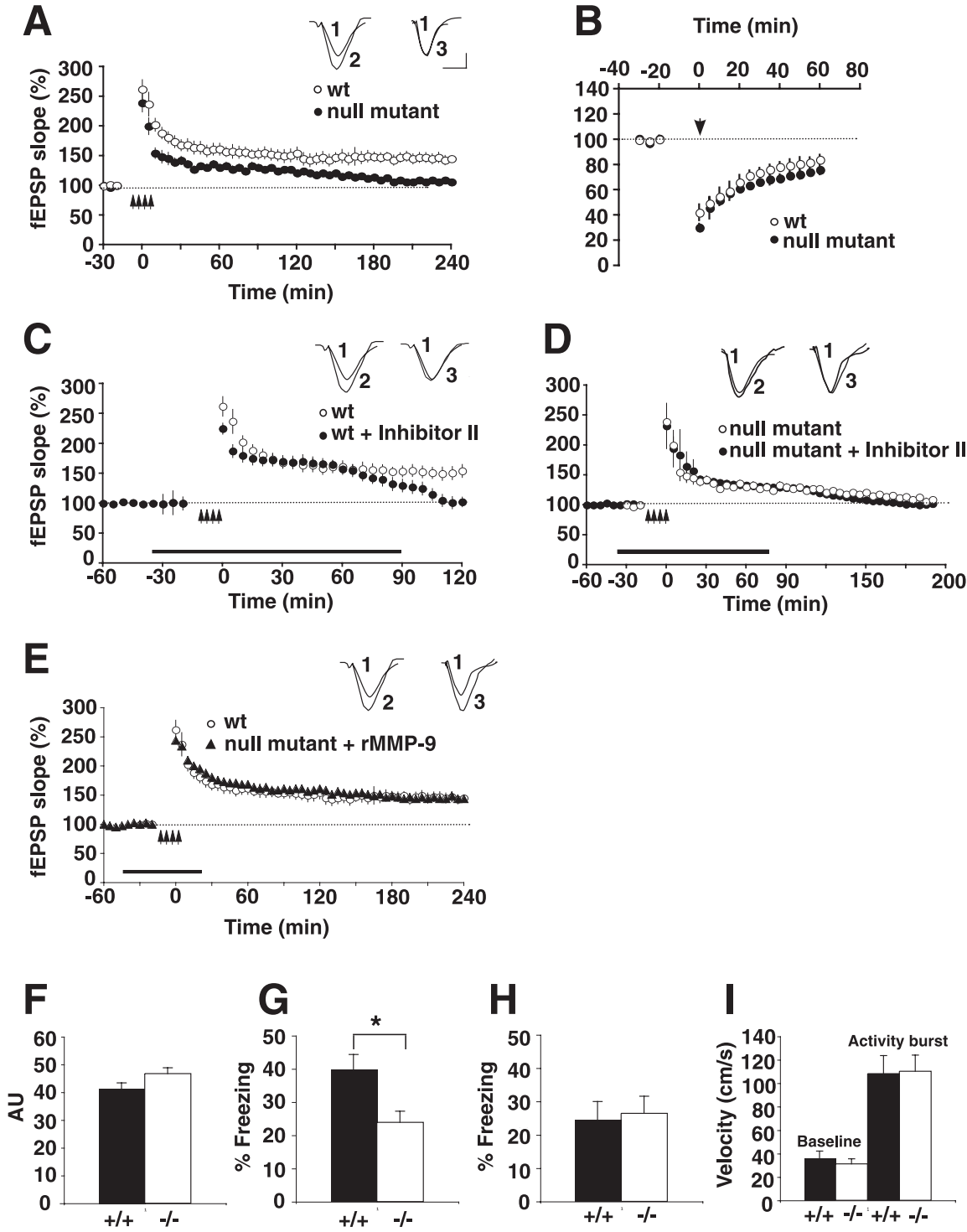

Figure 6. MMP-9 knock-out mice display impairments in LTP and hippocampal-dependent memory in a fear-conditioning memory task. $\boldsymbol{A}$, Tetanically induced LTP is significantly impaired in hippocampal slices from MMP-9 null-mutant mice (filled circles) compared with robust potentiation evident in wild-type slices (open circles). Arrows mark the stimulation (4 trains of 100 $\mathrm{Hz}$, $1 \mathrm{~s}$ stimulation separated by $5 \mathrm{~min} ; n=6$ slices; $n=3-4$ mice per genotype). Inset, Superimposed sample field potential recordings before (1) and $4 \mathrm{~h}$ after tetanization in wild-type (2) and MMP-9 null-mutant (3) mice. $\boldsymbol{B}$, Hippocampal slices from wild-type mice (open circles) or from MMP-9 null-mutant mice (filled circles) were stimulated tetanically (arrow) to produce NMDA receptor-dependent LTD. The synaptic depression was indistinguishable between genotypes, confirming that MMP-9 plays no role in LTD ( $n=4$ slices; $n=3-4$ mice per genotype). C, Wild-type mouse hippocampal slices subjected to tetanic L-LTP stimulation (as in $\boldsymbol{A}$ ) produces both E-LTP and a long-lasting L-LTP (open circles). In the presence of Inhibitor II (50 $\mu \mathrm{M}$; bar), normal E-LTP is elicited but L-LTP is abolished, shown by the return of the trace to baseline levels between 60 and 90 min (filled circles; $n=2$ slices; $n=2$ mice per condition). Inset, Superimposed sample field potential recordings before (1) and 120 min after tetanization in untreated (2) or inhibitor-treated (3) wild-type slices. D, Null-mutant hippocampal slices subjected to tetanic L-LTP stimulation (as in $\boldsymbol{A}$ ) in the presence of Inhibitor II ( $50 \mu \mathrm{m}$; bar) exhibit deficient LTP (filled circles) that is identical to that observed in untreated null-mutant slices (open circles; $n=2$ slices; $n=2$ mice per condition). Inset, Superimposed sample field potential recordings before (1) and 190 min after tetanization in untreated (2) or inhibitor-treated (3) null-mutant slices. $\boldsymbol{E}$, Pairing bath application of recombinant active MMP-9 (rMMP-9; bar) with four $100 \mathrm{HzL-LTP-inducing} \mathrm{tetanic} \mathrm{stimulation} \mathrm{(arrows)} \mathrm{in} \mathrm{null-mutanthippocampal} \mathrm{slices} \mathrm{completely} \mathrm{restores}$ both the magnitude and duration of LTP (filled diamonds) to levels indistinguishable from wild-type control mice (open circles; $n=3-4$ mice per genotype). Inset, Superimposed sample field potential recordings before (1) and $4 \mathrm{~h}$ after tetanization in untreated wild-type (2) or rMMP-9-treated null-mutant (3) mouse slices. $\boldsymbol{F}$, Baseline activity before training in MMP-9 knock-out (-/ - ) mice (open bar; $n=25$ ) is not significantly different than that in wild-type $(+/+)$ mice (filled bar; $n=27)\left(F_{(1,50)}=3.33 ; p=0.074\right)$. AU, Arbitrary units. $\mathbf{G}$, MMP-9 ${ }^{-1-}$ mutant mice display a significant deficit in long-term hippocampus-dependent memory for context when tested at $24 \mathrm{~h}$ compared with their wild-type littermate controls $\left(F_{(1,50)}=8.00{ }^{*}{ }^{*} p=0.007\right)$. H, MMP-9 ${ }^{-1-}$ mutant mice $(n=19)$ display normal amygdala-dependent cued conditioning compared with their wild-type littermates $(n=17)$ when tested at $30 \mathrm{~h}\left(F_{(1,33)}=0.069 ; p=\right.$ 0.80). I, Activity burst analysis shows no difference in shock perception between wild-type $(n=8)$ and MMP-9 ${ }^{-1-}$ mutantmice $(n=9)$. The velocity of the mice during a 2 s baseline before shock and 2 s during shock is shown $\left(F_{(1,15)}=1.51 ; p=0.70\right)$. Error bars indicate $S E M$. Calibration: $10 \mathrm{~ms}, 0.2 \mathrm{mV}$. wt, Wild type.
$30 \mathrm{~h}$ for cued conditioning (which is hippocampus independent) in context $B$, the mutants showed similar levels of freezing (Fig. 6H). Similar results were found when activity suppression, another natural fear response, was analyzed (supplemental Figs. S5, S6, available at www. jneurosci.org as supplemental material). This deficit in pavlovian fear conditioning was not attributable to enhanced perception of the footshock, because the mutant mice displayed similar activity bursts, an unconditioned response to the footshock, compared with wild-type mice (Fig. 6I).

\section{Discussion}

We demonstrate here novel roles for MMP-9 in normal hippocampal synaptic physiology, plasticity, and hippocampaldependent memory. This is striking because activation of MMPs in the brain is generally thought to be a protracted process associated with overt injury, excitotoxicity, or pathology (Yong et al., 2001). Our data demonstrate activation of MMPs over time scales faster than previously realized via $d y-$ namic processes that are part of normal synaptic function. We show using acute hippocampal slices that MMP-9 is rapidly and transiently activated in an NMDA receptorand protein synthesis-dependent manner during L-LTP. Pharmacological inhibitors of MMP-9 prevent induction of L-LTP selectively; MMP-9 has no role in, nor is regulated during, E-LTP, two different forms of LTD, or PPF. Mice with a targeted deletion of the MMP-9 gene also exhibit deficits in LTP, but not other forms of synaptic plasticity, that can be reversed by adding exogenous recombinant active MMP-9 to the null-mutant slices. At least one mechanism through which activated MMP-9 modulates hippocampal synaptic physiology is through integrin receptors, because integrin function-blocking reagents prevent an MMP-9mediated potentiation of synaptic signal strength in area CA1. The fundamental importance of MMP-9 function in modulating hippocampal synaptic physiology and plasticity is underscored by impairments in hippocampal-dependent long-term memory displayed by MMP-9 knock-out mice. Together, these data establish new, previously unrecognized functions for MMPs in synaptic and behavioral plasticity.

\section{Rapid upregulation of MMP-9 with L-LTP}

Several convergent lines of evidence presented here support the idea that MMP-9 is relatively rapidly upregulated by $30-60$ min after L-LTP-inducing stimuli. The increased level of the active form represents 
increased proteolytic activity, because in vivo zymography reveals significantly enhanced gelatinolytic activity in the potentiated slices that was blocked by MMP inhibitors. We show that such upregulation requires NMDA receptors. It is unlikely that this represents a nonspecific effect of intense synaptic depolarization resulting from trains of tetanic stimuli. First, it has been shown that NMDA receptor antagonists block induction of LTP specifically while leaving unchanged the strong depolarization mediated by AMPA receptor currents (Steward and Worley, 2001). Second, the other forms of synaptic plasticity that we tested all result in synaptic depolarization but had no effect on the levels of MMP-9. Thus, MMP-9 regulation occurs specifically in response to an NMDA receptor-mediated signaling pathway, which could be generated in neurons, glia, or both, because each of these cell types express NMDA receptors (Conti et al., 1997) and synthesize MMP-9 (Szklarczyk et al., 2002; Arai et al., 2003). Although the signal cascade involved remains to be determined, the observation that NMDA receptor-dependent LTD had no effect on levels of MMP-9 suggests that the NMDA receptor-mediated signal is specific to L-LTP. A likely candidate is $\mathrm{Ca}^{2+}$ influx, because distinct $\mathrm{Ca}^{2+}$-dependent signal cascades are thought to be generated by different forms of synaptic plasticity (Teyler et al., 1994).

The L-LTP-associated increase in levels of both pro- and active-MMP-9 is also blocked by inhibitors of protein synthesis. It is unclear at present whether MMP-9 gene transcription is involved, this being an important nexus of regulatory control of MMP levels in many other cell types (Sternlicht and Werb, 2001). Neuronal gene transcription can occur relatively rapidly in response to synaptic stimulation in the hippocampus. For example, cytoplasmic mRNA levels for the immediate-early gene Arc are significantly elevated within $30 \mathrm{~min}$ of synaptic stimulation in area CA1 and the dentate gyrus (Steward et al., 1998; Guzowski et al., 1999). Alternatively, the requirements of MMP-9 translation may be independent of transcription. It has been suggested that MMP-9 mRNA is dendritically localized (Szklarczyk et al., 2002); local translation of this pool of MMP-9 mRNA coupled with translation of basal levels of MMP-9 mRNA within glia that are situated within the neuropil of the stratum radiatum, where synapses are located, could in theory account for a rapid, local delivery of newly synthesized MMP-9 protein to sites of synaptic modification. It is not clear at present what regulatory steps are involved in the secretion of MMP-9 at these sites.

Our data do not distinguish whether the increased proteolytic activity within the neuropil shown by in vivo zymography derives directly from newly synthesized pro-MMP-9 or from activation of pre-existing basal pools of extracellularly located pro-MMP-9. Our data show a preexisting pool of pro-MMP-9 within unstimulated neuropil, consistent with other studies (Szklarczyk et al., 2002; Lee et al., 2004), which could be rapidly activated enzymatically. One possibility is that rapid conversion of pro- to activeMMP-9 is mediated via tissue plasminogen activator (tPA), a serine protease upregulated during, and required for, L-LTP (Qian et al., 1993; Huang et al., 1996; Baranes et al., 1998), because several tPA-dependent pathways have been shown to affect MMP-9 levels and/or activity in non-neuronal cell types (Cuzner and Opdenakker, 1999; Wang et al., 2003b). The mechanism by which L-LTP-induced levels of active MMP-9 are returned to prestimulation levels is unclear, although activity-dependent regulation of endogenous TIMPs is possible (Rivera et al., 1997; Jaworski et al., 1999).

\section{Mechanisms by which MMP-9 activity modulates synaptic and behavioral plasticity}

Our data suggest that at least one way in which active MMP-9 modulates hippocampal synaptic function is through integrin receptors. It is well established on pharmacological and genetic grounds that RGD-binding integrins are essential for long-term stabilization of hippocampal LTP and certain forms of hippocampal-dependent memory (Staubli et al., 1990; Chun et al., 2001; Chan et al., 2003). Identifying the upstream events that lead to integrin activation during such synaptic and behavioral plasticity has been elusive. We show that exposing hippocampal slices to recombinant-active MMP-9 produces a dosedependent, slowly emerging synaptic potentiation that is abrogated by a variety of pharmacologically distinct types of integrin blockers (neutralizing antibodies, synthetic RGD-blocking peptides, and disintegrins). These data suggest a model in which MMP-9 acts upstream of integrin receptor activation to modulate synaptic plasticity (supplemental Fig. S7, available at www.jneurosci.org as supplemental material). Speculatively, MMP-9 cleavage of target matrix or cell-surface proteins harboring latent RGD-recognition sequences may, after exposure, activate integrin-dependent signaling cascades (Nagase and Woessner, 1999). The time course and magnitude of the MMP-9-induced potentiation is similar to that which emerges after integrin activation and is presumably based on the integrin-activated signal cascades shown previously to result in a slowly emerging enhancement of glutamate receptor-mediated currents (Kramar et al., 2003; Lin et al., 2003). Alternatively, it is possible that MMP-9 binds directly to synaptic integrins, which in turn optimally anchor or position them to cleave other target substrates (Fridman et al., 2003; Wang et al., 2003a).

MMP-9 may also contribute to synaptic plasticity by enabling structural synaptic remodeling similar to that associated with activity-dependent plasticity (Huntley et al., 2002), akin to the role attributed to $\mathrm{tPA}$ in dendritic spine remodeling (Mataga et al., 2004; Oray et al., 2004). This could occur via MMP cleavage of matrix or adhesion proteins that, together, normally provide the structural scaffolding that maintains synaptic architecture (Benson et al., 2000; Dityatev and Schachner, 2003). The cadherin family of synaptic adhesion proteins, for example, are associated with structural remodeling during L-LTP (Tang et al., 1998; Bozdagi et al., 2000; Murase et al., 2002), and in some cell types, are targets for MMPdependent cleavage (Steinhusen et al., 2001).

Both genetic and pharmacological block of MMP-9 function were consistent in showing a significant role for MMP-9 selectively in LTP but not other forms of synaptic plasticity. Nevertheless, the deficits in LTP observed in null-mutant mouse slices differed somewhat from the deficits in LTP achieved by acute pharmacological blockade in rat or wild-type mouse slices. Although we ruled out age and species differences, as well as potentially spurious effects of the pharmacological inhibitors, it cannot be ruled out at this time that compensatory changes in the genetically manipulated animals could have contributed. For example, NMDA receptor function could be somehow impaired by the genetic deletion, although any such effects would presumably be LTP specific, because we found normal NMDA receptordependent LTD in the null-mutant slices. This could, in theory, reflect changes in specific NMDA receptor subunits, because different subunits are thought to contribute differentially to LTP and LTD (Liu et al., 2004; Massey et al., 2004), although this is not universally agreed on (Barria and Malinow, 2005). The fact that exogenous recombinant active MMP-9 was able to completely and essentially immediately restore the deficits in LTP suggests a 
more acute role for MMP-9 in LTP. This leaves open a second possibility that MMP-9 may contribute to LTP both by acting as a ligand for a receptor (which would have been blocked genetically but not necessarily pharmacologically) as well as through its proteolytic activity (blocked both genetically and pharmacologically). The protease tPA, for example, contributes to LTP both through enzymatic cleavage of pro-BDNF as well as binding to its cell-surface low-density lipoprotein receptor-related protein receptor (Zhuo et al., 2000; Pang et al., 2004). In any event, the deficits in LTP displayed by the null-mutant mice parallel the deficits in hippocampal-dependent fear conditioning, which, on the one hand, is perhaps not surprising given that long-lasting protein synthesis-dependent forms of synaptic plasticity such as LTP are thought to contribute to long-term memory (Bliss and Collingridge, 1993; Silva, 2003). On the other hand, conclusions about the role of MMP-9 in memory should be regarded as tentative, and although it is possible that MMP-9 contributes to hippocampal-dependent memory by modulating long-lasting synaptic plasticity through mechanisms we have detailed here, definitive tests of this await future studies.

\section{References}

Anagnostaras SG, Josselyn SA, Frankland PW, Silva AJ (2000) Computerassisted behavioral assessment of Pavlovian fear conditioning in mice. Learn Mem 7:58-72.

Arai K, Lee SR, Lo EH (2003) Essential role for ERK mitogen-activated protein kinase in matrix metalloproteinase- 9 regulation in rat cortical astrocytes. Glia 43:254-264.

Bahr BA, Staubli U, Xiao P, Chun D, Ji Z-X, Esteban ET, Lynch G (1997) Arg-gly-asp-ser-selective adhesion and the stabilization of long-term potentiation: pharmacological studies and the characterization of a candidate matrix receptor. J Neurosci 17:1320-1329.

Baranes D, Lederfein D, Huang YY, Chen M, Bailey CH, Kandel ER (1998) Tissue plasminogen activator contributes to the late phase of LTP and to synaptic growth in the hippocampal mossy fiber pathway. Neuron 21:813-825.

Barria A, Malinow R (2005) NMDA receptor subunit composition controls synaptic plasticity by regulating binding to CaMKII. Neuron 48:289-301.

Benson DL, Schnapp L, Shapiro L, Huntley GW (2000) Making memories stick: cell -adhesion molecules in synaptic plasticity. Trends Cell Biol 10:473-482.

Bliss TVP, Collingridge GL (1993) A synaptic model of memory: long-term potentiation in the hippocampus. Nature 361:31-39.

Bliss TVP, Lømo T (1973) Long-lasting potentiation of synaptic transmission in the dentate area of the anesthetized rabbit following stimulation of the perforant path. J Physiol (Lond) 232:331-356.

Bozdagi O, Shan W, Tanaka H, Benson DL, Huntley GW (2000) Increasing numbers of synaptic puncta during late-phase LTP: N-cadherin is synthesized, recruited to synaptic sites, and required for potentiation. Neuron 28:245-259.

Calabresi P, Napolitano M, Centonze D, Marfia GA, Gubellini P, Teule MA, Berretta N, Bernardi G, Frati L, Tolu M, Gulino A (2000) Tissue plasminogen activator controls multiple forms of synaptic plasticity and memory. Eur J Neurosci 12:1002-1012.

Castillo PE, Schoch S, Schmitz F, Sudhof TC, Malenka RC (2002) RIM1alpha is required for presynaptic long-term potentiation. Nature 415:327-330.

Chan CS, Weeber EJ, Kurup S, Sweatt JD, Davis RL (2003) Integrin requirement for hippocampal synaptic plasticity and spatial memory. J Neurosci 23:7107-7116.

Chun D, Gall CM, Bi X, Lynch G (2001) Evidence that integrins contribute to multiple stages in the consolidation of long term potentiation in rat hippocampus. Neuroscience 105:815-829.

Collingridge GL, Bliss TVP (1987) NMDA receptors-their role in long-term potentiation. Trends Neurosci 10:288-293.

Conti F, Minelli A, DeBiasi S, Melone M (1997) Neuronal and glial localization of NMDA receptors in the cerebral cortex. Mol Neurobiol 14:1-18.

Cuzner ML, Opdenakker G (1999) Plasminogen activators and matrix metalloproteases, mediators of extracellular proteolysis in inflammatory demyelination of the central nervous system. J Neuroimmunol 94:1-14.
Dityatev A, Schachner M (2003) Extracellular matrix molecules and synaptic plasticity. Nat Rev Neurosci 4:456-468.

Dudek SM, Bear MF (1992) Homosynaptic long-term depression in area CA1 of hippocampus and effects of $N$-methyl-D-aspartate receptor blockade. Proc Natl Acad Sci USA 89:4363-4367.

Eichenbaum H, Otto T, Cohen NJ (1992) The hippocampus-what does it do? Behav Neural Biol 57:2-36.

Engert F, Bonhoeffer T (1999) Dendritic spine changes associated with hippocampal long-term synaptic plasticity. Nature 399:66-70.

Frey U, Krug M, Reymann KG, Matthies H (1988) Anisomycin, an inhibitor of protein synthesis, blocks late phases of LTP phenomena in the hippocampal CA1 region in vitro. Brain Res 452:57-65.

Frey U, Huang YY, Kandel ER (1993) Effects of cAMP simulate a late stage of LTP in hippocampal CA1 neuron. Science 260:1661-1664.

Fridman R, Toth M, Chvyrkova I, Meroueh SO, Mobashery S (2003) Cell surface association of matrix metalloproteinase-9 (gelatinase B). Cancer Metastasis Rev 22:153-166.

Guzowski JF, McNaughton BL, Barnes CA, Worley PF (1999) Environment-specific expression of the immediate-early gene Arc in hippocampal neuronal ensembles. Nat Neurosci 2:1120-1124.

Huang YY, Bach ME, Lipp HP, Zhuo M, Wolfer DP, Hawkins RD, Schoonjans L, Kandel ER, Godfraind JM, Mulligan R, Collen D, Carmeliet P (1996) Mice lacking the gene encoding tissue-type plasminogen activator show a selective interference with late-phase long-term potentiation in both Schaffer collateral and mossy fiber pathways. Proc Natl Acad Sci USA 93:8699-8704.

Huber KM, Kayser MS, Bear MF (2000) Role for rapid dendritic protein synthesis in hippocampal mGluR-dependent long-term depression. Science 288:1254-1257.

Huntley GW, Benson DL, Colman DR (2002) Structural remodeling of the synapse in response to physiological activity. Cell 108:1-4.

Hynes RO (1992) Integrins: versatility, modulation, and signaling in cell adhesion. Cell 69:11-25.

Impey S, Mark M, Villacres EC, Poser S, Chavkin C, Storm DR (1996) Induction of CRE-mediated gene expression by stimuli that generate longlasting LTP in area CA1 of the hippocampus. Neuron 16:973-982.

Jaworski J, Biedermann IW, Lapinska J, Szklarczyk A, Figiel I, Konopka D, Nowicka D, Filipkowski RK, Hetman M, Kowalczyk A, Kaczmarek L (1999) Neuronal excitation-driven and AP-1-dependent activation of tissue inhibitor of metalloproteinases-1 gene expression in rodent hippocampus. J Biol Chem 274:28106-28112.

Jourquin J, Tremblay E, Decanis N, Charton G, Hanessian S, Chollet AM, Le Diguardher T, Khrestchatisky M, Rivera S (2003) Neuronal activitydependent increase of net matrix metalloproteinase activity is associated with MMP-9 neurotoxicity after kainate. Eur J Neurosci 18:1507-1517.

Kim JJ, Fanselow MS (1992) Modality-specific retrograde amnesia of fear. Science 256:675-677.

Komai S, Matsuyama T, Matsumoto K, Kato K, Kobayashi M, Imamura K, Yoshida S, Ugawa S, Shiosaka S (2000) Neuropsin regulates an early phase of schaffer-collateral long-term potentiation in the murine hippocampus. Eur J Neurosci 12:1479-1486.

Kramar EA, Bernard JA, Gall CM, Lynch G (2003) Integrins modulate fast excitatory transmission at hippocampal synapses. J Biol Chem 278:10722-10730.

Lee SR, Tsuji K, Lo EH (2004) Role of matrix metalloproteinases in delayed neuronal damage after transient global cerebral ischemia. J Neurosci 24:671-678.

Liao D, Jones A, Malinow R (1992) Direct measurement of quantal changes underlying long-term potentiation in CA1 hippocampus. Neuron 9:1089-1097.

Lin B, Arai AC, Lynch G, Gall CM (2003) Integrins regulate NMDA receptor-mediated synaptic currents. J Neurophysiol 89:2874-2878.

Liu L, Wong TP, Pozza MF, Lingenhoehl K, Wang Y, Sheng M, Auberson YP, Wang YT (2004) Role of NMDA receptor subtypes in governing the direction of hippocampal synaptic plasticity. Science 304:1021-1024.

Madani R, Hulo S, Toni N, Madani H, Steimer T, Muller D, Vassalli JD (1999) Enhanced hippocampal long-term potentiation and learning by increased neuronal expression of tissue-type plasminogen activator in transgenic mice. EMBO J 18:3007-3012.

Massey PV, Johnson BE, Moult PR, Auberson YP, Brown MW, Molnar E, Collingridge GL, Bashir ZI (2004) Differential roles of NR2A and 
NR2B-containing NMDA receptors in cortical long-term potentiation and long-term depression. J Neurosci 24:7821-7828.

Mataga N, Mizuguchi Y, Hensch TK (2004) Experience-dependent pruning of dendritic spines in visual cortex by tissue plasminogen activator. Neuron 44:1031-1041.

Murase S, Mosser E, Schuman EM (2002) Depolarization drives betacatenin into neuronal spines promoting changes in synaptic structure and function. Neuron 35:91-105.

Nagase H, Woessner Jr JF (1999) Matrix metalloproteinases. J Biol Chem 274:21491-21494.

Nägerl UV, Eberhorn N, Cambridge SB, Bonhoeffer T (2004) Bidirectional activity-dependent morphological plasticity in hippocampal neurons. Neuron 44:759-767.

Nguyen PV, Abel T, Kandel ER (1994) Requirement of a critical period of transcription for induction of a late phase of LTP. Science 265:1104-1107.

Oh LY, Larsen PH, Krekoski CA, Edwards DR, Donovan F, Werb Z, Yong VW (1999) Matrix metalloproteinase-9/gelatinase B is required for process outgrowth by oligodendrocytes. J Neurosci 19:8464-8475.

Oray S, Majewska A, Sur M (2004) Dendritic spine dynamics are regulated by monocular deprivation and extracellular matrix degradation. Neuron 44:1021-1030.

Otmakhov N, Khibnik L, Otmakhova N, Carpenter S, Riahi S, Asrican B, Lisman J (2004) Forskolin-induced LTP in the CA1 hippocampal region is NMDA receptor dependent. J Neurophysiol 91:1955-1962.

Pang PT, Teng HK, Zaitsev E, Woo NT, Sakata K, Zhen S, Teng KK, Yung WH, Hempstead BL, Lu B (2004) Cleavage of proBDNF by tPA/plasmin is essential for long-term hippocampal plasticity. Science 306:487-491.

Qian Z, Gilbert ME, Colicos MA, Kandel ER, Kuhl D (1993) Tissueplasminogen activator is induced as an immediate-early gene during seizure, kindling and long-term potentiation. Nature 361:453-457.

Reeves TM, Prins ML, Zhu J, Povlishock JT, Phillips LL (2003) Matrix metalloproteinase inhibition alters functional and structural correlates of deafferentation-induced sprouting in the dentate gyrus. J Neurosci 23:10182-10189.

Rivera S, Tremblay E, Timsit S, Canals O, Ben-Ari Y, Khrestchatisky M (1997) Tissue inhibitor of metalloproteinases-1 (TIMP-1) is differentially induced in neurons and astrocytes after seizures: evidence for developmental, immediate early gene, and lesion response. J Neurosci 17:4223-4235.

Shapiro ML, Eichenbaum H (1999) Hippocampus as a memory map: synaptic plasticity and memory encoding by hippocampal neurons. Hippocampus 9:365-384.

Shi SH, Hayashi Y, Petralia RS, Zaman SH, Wenthold RJ, Svoboda K, Malinow R (1999) Rapid spine delivery and redistribution of AMPA receptors after synaptic NMDA receptor activation. Science 284:1811-1816.

Silva AJ (2003) Molecular and cellular cognitive studies of the role of synaptic plasticity in memory. J Neurobiol 54:224-237.

Silva AJ, Stevens CF, Tonegawa S, Wang Y (1992) Deficient hippocampal long term potentiation in $\alpha$-calcium-calmodulin kinase II mutant mice. Science 257:201-205.
Staubli U, Vanderklish P, Lynch G (1990) An inhibitor of integrin receptors blocks long-term potentiation. Behav Neural Biol 53:1-5.

Steinhusen U, Weiske J, Badock V, Tauber R, Bommert K, Huber O (2001) Cleavage and shedding of E-cadherin after induction of apoptosis. J Biol Chem 276:4972-4980.

Sternlicht MD, Werb Z (2001) How matrix metalloproteinases regulate cell behavior. Annu Rev Cell Dev Biol 17:463-516.

Steward O, Worley PF (2001) Selective targeting of newly synthesized Arc mRNA to active synapses requires NMDA receptor activation. Neuron $30: 227-240$.

Steward O, Wallace CS, Lyford GL, Worley PF (1998) Synaptic activation causes the mRNA for the IEG Arc to localize selectively near activated postsynaptic sites on dendrites. Neuron 21:741-751.

Szklarczyk A, Lapinska J, Rylski M, McKay RD, Kaczmarek L (2002) Matrix metalloproteinase- 9 undergoes expression and activation during dendritic remodeling in adult hippocampus. J Neurosci 22:920-930.

Tang L, Hung CP, Schuman EM (1998) A role for the cadherin family of cell adhesion molecules in hippocampal long-term potentiation. Neuron 20:1165-1175.

Teyler TJ, Cavus I, Coussens C, DiScenna P, Grover L, Lee YP, Little Z (1994) Multideterminant role of calcium in hippocampal synaptic plasticity. Hippocampus 4:623-634.

Toni N, Buchs PA, Nikonenko I, Bron CR, Muller D (1999) LTP promotes formation of multiple spine synapses between a single axon terminal and a dendrite. Nature 402:421-425.

Vu TH, Shipley JM, Bergers G, Berger JE, Helms JA, Hanahan D, Shapiro SD, Senior RM, Werb Z (1998) MMP-9/gelatinase B is a key regulator of growth plate angiogenesis and apoptosis of hypertrophic chondrocytes. Cell 93:411-422.

Wang X, Lee SR, Arai K, Tsuji K, Rebeck GW, Lo EH (2003b) Lipoprotein receptor-mediated induction of matrix metalloproteinase by tissue plasminogen activator. Nat Med 9:1313-1317.

Wang XQ, Sun P, Paller AS (2003a) Ganglioside GM3 inhibits matrix metalloproteinase- 9 activation and disrupts its association with integrin. J Biol Chem 278:25591-25599.

Yong VW, Power C, Forsyth P, Edwards DR (2001) Metalloproteinases in biology and pathology of the nervous system. Nat Rev Neurosci 2:502-511.

Zhang JW, Gottschall PE (1997) Zymographic measurement of gelatinase activity in brain tissue after detergent extraction and affinity-support purification. J Neurosci Methods 76:15-20.

Zhang JW, Deb S, Gottschall PE (1998) Regional and differential expression of gelatinases in rat brain after systemic kainic acid or bicuculline administration. Eur J Neurosci 10:3358-3368.

Zhou Q, Homma KJ, Poo MM (2004) Shrinkage of dendritic spines associated with long-term depression of hippocampal synapses. Neuron 44:749-757.

Zhuo M, Holtzman DM, Li Y, Osaka H, DeMaro J, Jacquin M, Bu G (2000) Role of tissue plasminogen activator receptor LRP in hippocampal longterm potentiation. J Neurosci 20:542-549. 